\title{
ANALISA KERUSAKAN FORMASI AKIBAT PEKERJAAN PERFORASI DENGAN MENGGUNAKAN METODA YILDIZ PADA SUMUR FR 168, SUMUR 154, DAN SUMUR 148 DILAPANGAN X
}

(Analisys of Formation Damage Due to Perforation Work Using Yildiz Methods On well FR 168,154 dan148, Field X)

\author{
ALIMUSNAL \\ Jurusan Teknik Perminyakan Fakultas Teknik Universitas Islam Riau \\ Jln Kaharuddin Nst No 113 Pekanbaru 28284 \\ ulpti@yahoo.co.id
}

\begin{abstract}
Abstrak
Komplesi perforasi merupakan salah satu alternatif penyelesaian sumur untuk formasi yang tidak kompak. Perforasi dilakukan pada lapisan produktif dengan cara membuat lubang pada casing sebagai penghubung antara lapisan produktif dengan lubang sumur, sehingga terjadi aliran fluida dari formasi kelubang sumur. Pada umumnya ketika kegiatan perforasi dilakukan akan terjadi kerusakan sumur yang ditandai dengan adanya skin. Untuk menentukan besarnya harga skin yang di akibatkan oleh perforasi tersebut pada penelitian ini diterapkan metoda Yildiz. Perhitungan skin diperoleh berturut turut pada sumur FR 168,154 dan 148 adalah 6.835,6.784 dan7.610. Berdasarkan skin tersebut diperoleh produktivitas indeks (PI)berturut turut adalah $0.10 \mathrm{bpd} / \mathrm{psi}, 1.86$ bpd/psi dan 0,24 bpd/psi serta harga laju produksi (Q) berturut-turut adalah 168.297 bfpd, 1151.533 bfpd dan 371.271 bfpd. Dari perbandingan kedua parameter hasil perhitungan Q dan PI menggunakan metoda Yildiz menghasilkan harga yang lebih besar dibandingkan harga dari aktualnya.
\end{abstract}

Kata-kata kunci: Skin,Produktivitas Indeks,laju alir fluida reservoir.

\begin{abstract}
Perforation of complation is one alternative of the well complation as special for unconsolidated formation. Perforation implemented on produvtive layer by doing a hole on the casing that connected between productive layers and the well hole. In general when perforation carried out will be damage to the well characterized by the skin. To determine $\mathrm{n}$ the value of skin that resulted by perforation in this research by using Yildiz Method. The calculation result of skin from well \# FR 168, well \# 154 and well \# 148 respectively are 6.835, 6.784 dan 7.610. Based on the value of skin resulted the Productivity indeks(PI) for well \# FR 168, well \# 154 and well \# 148 respectively are $0.10 \mathrm{bpd} / \mathrm{psi}, 1.86 \mathrm{bpd} / \mathrm{psi}$ and $0,24 \mathrm{bpd} / \mathrm{psi}$, while the value of production rate $(\mathrm{Q})$ for each well can be culated.
\end{abstract}

Keywords: Skin,Productivitas Indeks, Rate.

\section{PENDAHULUAN}

Kerusakan formasi adalah salah satu faktor yang mempengaruhi laju produksi. Hal ini dikarena adanya faktor skin yang diakibatkan oleh perforasi yang dilakukan pada sumur. Sehubungan dengan hal tersebut perlu dilakukan perhitungan Skin. Perhitungan skin pada penelitian ini dilakukan dengan metoda Yeldis dan setelah nilai skin di peroleh, maka laju 
produksi yang dihasilkan keseluruhannya dapat dihitung hal ini akan menunjukkan besarnya Produkstifitas Indeks.

Produktivitas sumur minyak dipengaruhi oleh berbagai faktor diantaranya propertis fluida, komplesi sumur, Formation damage (skin), dan lain-lain. Kerusakan Formasi adalah merupakan perusakan/penurunan permeabilitas di sekitar daerah lubang bor. Adanya kerusakan formasi dapat menurunkan produktivitas sumur. Pengaruh kerusakan formasi terbatas pada daerah di sekitar lubang bor, Sedangkan dalam penelitian ini akan menghitung efek kerusakan formasi dinyatakan dalam skin faktor $\left(\mathrm{s}_{\mathrm{d}}\right)$.

\section{Metoda Penelitian}

Penulisan penelitian ini berdasarkan hasil studi Pustaka dan diaplikasikan dengan data lapangan, kemudian menganalisa sesuai dengan teori yang didapatkan dari literatur.

\section{TEORI DASAR METODA YILDIZ}

Pekerjaan perforasi merupakan bagian dari penyelesaian suatu sumur minyak. Sesudah pipa selubung produksi disemen dan kepala sumur (well head) selesai dipasang dan diset dengan baik, maka kegiatan selanjutnya adalah perforasi di zona produktif yang telah ditentukan. Gambar 1 menunjukan bentuk penyelesaian sumur perforasi dengan Formation Damage dan parameter crushed zone. 


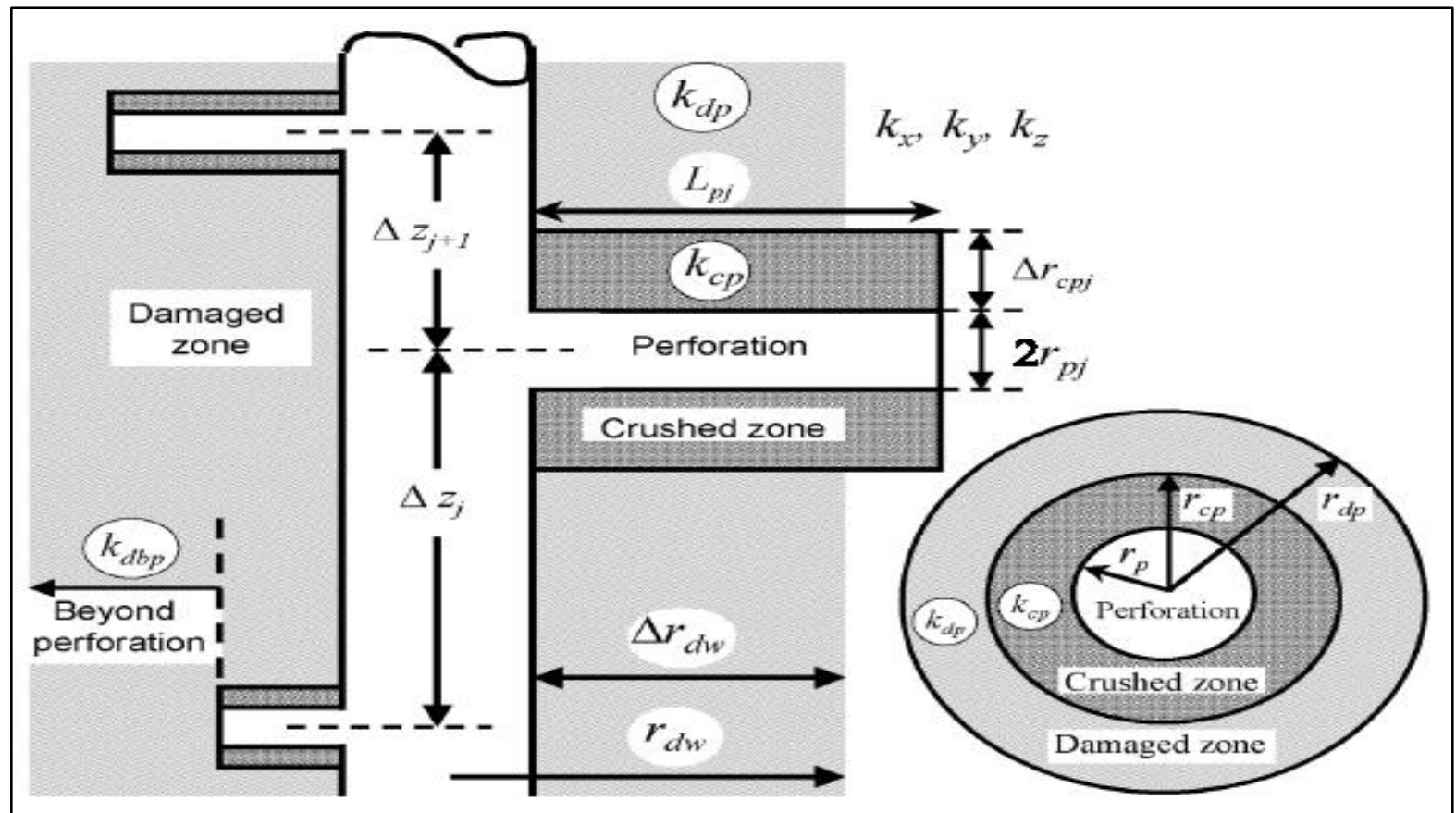

Gambar.1. Bentuk Sumur Perforasi Dengan Formation Damage dan parameter crushed zone

Yildis melakukan perhitungan terhadap faktor skin yang diakibatkan oleh perforasi dengan menerapkan dan memodifikasi persamaan yang diterapkan oleh Karakas-Tariq. Langkahlangkah dalam menentukan skin pada saat perforasi sebagai berikut :

1. Hitung skin disaat aliran konvergen secara horizontal dengan persamaan :

$$
S H=\ln \left(\frac{r_{w}}{r_{w e}}\right), \quad r_{w e}\left(\theta_{p}\right)=\alpha\left(\theta_{p}\right) *\left(r_{w}+L_{p}\right)
$$

Dimana : $r_{w e}$ adalah radius sumur yang efektif, dapat ditentukan konstantanya pada tabel dibawah ini:

Tabel 1. Phasa penembakan

\begin{tabular}{|c|c|c|c|c|c|c|c|}
\hline Perforation Phasing & $\mathbf{a} \theta$ & a1 & $\mathbf{a} 2$ & b1 & b2 & $\mathbf{c}_{1}$ & $\mathbf{c}_{2}$ \\
\hline $0^{\circ}\left(360^{\circ}\right)$ & 0.250 & -2.091 & 0.0453 & 35.1313 & 31.8672 & $21.6 \mathrm{E}-1$ & 12.675 \\
\hline $180^{\circ}$ & 0.500 & -2.025 & 0.0943 & 3.037 & 31.8115 & $52.6 \mathrm{E}-2$ & 24.532 \\
\hline $120^{\circ}$ & 0.648 & -2.018 & 0.0634 & +1.6136 & 61.7770 & $6.6 \mathrm{E}-3$ & 3.320 \\
\hline $90^{\circ}$ & 0.726 & -1.905 & 0.1038 & 1.5674 & 41.6935 & $51.9 \mathrm{E}-3$ & 36.155 \\
\hline $60^{\circ}$ & 0.813 & -1.898 & 0.1023 & 1.3654 & 41.3490 & $3.0 \mathrm{E}-4$ & +7.509 \\
\hline $45^{\mathrm{O}}$ & 0.860 & -1.788 & 0.2398 & 1.1915 & 51.6392 & $2.6 \mathrm{E}-5$ & 58.791 \\
\hline
\end{tabular}

2. Hitung skin wellbore dengan persamaan :

$$
S_{w b}(\theta)=C_{1}(\theta) \operatorname{EXP}\left[C_{2}(\theta) r_{W D}\right], \quad r_{w} D=\frac{r_{w}}{\left(r_{w}+L p\right)}
$$


$\mathrm{C}_{1}$ dan $\mathrm{C}_{2}$ dapat dilihat pada tabel di atas untuk berbagai macam phasa penembakan.

3. Hitung skin vertikal dengan persamaan :

$$
\begin{aligned}
& \Delta z_{p_{D}}=\Delta z_{p} \sqrt{\frac{\left(\frac{k_{r}}{k_{z}}\right)}{L_{p}}} \quad \Delta z_{p}=\frac{1}{n_{s p f}} \\
& r_{p D}=\left(\frac{r_{p}}{2 * \Delta z_{p}}\right) *\left(1+\sqrt{\frac{k_{z}}{k_{r}}}\right) \\
& a=a_{1}\left(\theta_{p}\right) * \log \left(r_{p D}\right)+a_{2}\left(\theta_{p}\right) \\
& b=b_{1}\left(\theta_{p}\right) * r_{p D}+b_{2}\left(\theta_{p}\right), \quad S v=10^{a} * \Delta z_{p D}^{b-1} * r_{p D}^{b}
\end{aligned}
$$

dimana $a_{1}, a_{2}, b_{1}$, dan $b_{2}$ dapat dilihat pada tabel phasa penembakan diatas.

4.Tentukan skin perforasi:

$$
S_{p}=S_{H}+S_{V}+S_{w b}
$$

5. effek crushed zone dapat ditentukan :

pertama, perkirakan faktor skin disaat zona yang rusak disekitar daerah perforasi.

$$
S_{c z}^{\prime}=\frac{\Delta z_{p}}{L p} *\left(\frac{k}{k_{c z}}-1\right) * \ln \left(\frac{r_{c z}}{r_{p}}\right), \quad S_{p c}=S_{p}+S_{c z}^{\prime}
$$

6. Menentukan harga skin damage formasi $\left(\mathrm{S}_{\mathrm{pdc}}\right)$.

$$
S_{p d c}=S_{d}+\frac{k}{k_{d}} *\left(S_{p}+S x\right), \text { Sx dapat diabaikan }
$$

7. $\quad h_{d}=\frac{h / L p}{\sqrt{k_{H} / k_{v}}}$

Dimensionless perforation radius

$$
r_{p D}=\left(\frac{r_{p}}{2 * \Delta z_{p}}\right) *\left(1+\sqrt{\frac{k_{z}}{k_{r}}}\right) \quad \text { dimana: } \mathrm{r}_{\mathrm{pD}}=\text { radius perforasi, } \mathrm{ft}
$$

8. Dimensionless well radius

$$
\begin{aligned}
& r_{w D}=\frac{r_{w}}{L p+r_{w}} \\
& \text { dimana: } \mathrm{r}_{\mathrm{w}}=\text { radius sumur, } \\
& S_{w b}(\theta)=C_{1}(\theta) E X P\left[C_{2}(\theta) r_{w d}\right]
\end{aligned}
$$

Untuk : $0.30 \leq \mathrm{r}_{\mathrm{wd}} \leq 0.90, \mathrm{C}_{1}$ dan $\mathrm{C}_{2}$ pada Tabel dibawah ini:

Tabel.2. Koofesien Korelasi skin vertikal 


\begin{tabular}{|c|c|c|c|c|c|c|c|}
\hline Perforation Phasing & $\mathbf{a} \theta$ & a1 & $\mathbf{a} 2$ & $\mathbf{b}_{1}$ & $\mathbf{b}_{2}$ & $\mathbf{c}_{1}$ & $\mathbf{c}_{2}$ \\
\hline $0^{\circ}\left(360^{\circ}\right)$ & 0.250 & \multicolumn{6}{|c|}{ 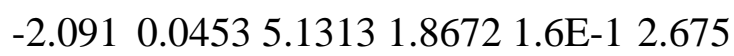 } \\
\hline $180^{\circ}$ & 0.500 & -2.025 & 0.09 & 33.0 & 31.8 & 52.61 & 24.532 \\
\hline $120^{\circ}$ & 0.648 & -2.018 & 0.06 & 41.6 & 61. & 06.6 & 35.320 \\
\hline $90^{\circ}$ & 0.726 & -1.905 & 0.1 & 81.5 & 41. & 51. & 36.155 \\
\hline $60^{\circ}$ & 0.813 & -1.898 & 0.10 & 31.3 & 41.3 & 03.01 & 47.509 \\
\hline $45^{\mathrm{O}}$ & 0.860 & -1.788 & 0.23 & 81.1 & 51.6 & 24.61 & 58.791 \\
\hline
\end{tabular}

Secara formulasi skin pada zona terkompaksi dalam sumur dapat ditentukan dengan :

$$
\begin{aligned}
& S_{c}=\left[\frac{h}{L p}\left(\frac{k}{k_{c}}-1\right)\right] \ln \frac{r_{c}}{r_{p}}, \quad S_{d}=\left(\frac{k}{k_{d}}-1\right)\left[\ln \left(\frac{r_{d}}{r_{w}}\right)+S p\right]+\frac{k}{k_{d}} \\
& h_{b D}=\frac{h_{b}}{h}, \quad D=\left|\frac{\left(1-h_{p D}\right) \mid}{2-h_{b D}}\right| \quad r_{w D}=r_{w} \sqrt{\left(\frac{k_{z}}{k_{r}}\right)} \frac{z^{\prime}}{h}, \\
& z_{1}=1-2 D, \quad z_{2}=1-2 D+h_{p D}, z_{3}=1-2 D-h_{p D} \\
& g(y)=r_{w D} * \frac{\ln \left[\sin ^{2}\left(\frac{\pi * y}{2}\right)+0.1053 * r_{w D}^{2}\right]}{\pi} \\
& f(y)=y * \ln y+(2-y) * \ln (2-y)+g(y) \\
& F=f(0)-f\left(h_{p D}\right)+f\left(z_{1}\right)-0.5\left[f\left(z_{2}\right)+f\left(z_{3}\right)\right] \\
& S_{p p}=\left(\frac{1}{h_{p D}}-1\right) *\left(1.2704-\ln r_{w D}\right)-\frac{F}{h_{p D}^{2}} \\
& S_{\mathrm{pp}}=\operatorname{Skin~penetrasi~parsial~} \\
& S p=S p p c=\frac{h}{h p} \operatorname{Spcf}
\end{aligned}
$$

dimana: $\quad \mathrm{h}=$ jarak vertikal antara dua perforasi, $\mathrm{ft}$ $\mathrm{hp}=$ ketebalan zona perforasi, $\mathrm{ft}$

Untuk interval yang diproduksi secara partial komplesi (sebagian), skin perforasinya dapat juga dihitung dengan persamaan berikut :

$$
\mathrm{Sa}=\left(\frac{h}{\text { Bot.Perf-Top.Perf }}\right) x \ln \left(\frac{h}{r w / 24}\right) \times\left(\frac{K v}{K h}\right)^{0.5}-2
$$




$$
\begin{aligned}
& S p=\operatorname{SppcD}=\frac{k f . h}{k s \cdot h p} \operatorname{Spcf} \\
& \begin{aligned}
& S d= \frac{k f-k s}{k s} \ln \frac{r s}{r w} \\
& \text { dimana }: \mathrm{rs}=\text { radius skin, } \mathrm{ft} \\
& \mathrm{rw}=\text { radius well, } \mathrm{ft} \\
& S_{\text {true }}=\frac{h}{h p} S d \cdot \ln \frac{r s}{r w} \\
& \text { jadi skin total }(\mathrm{St})=\mathrm{Sp}+\mathrm{S}_{\text {true }}+\mathrm{Sa}
\end{aligned}
\end{aligned}
$$
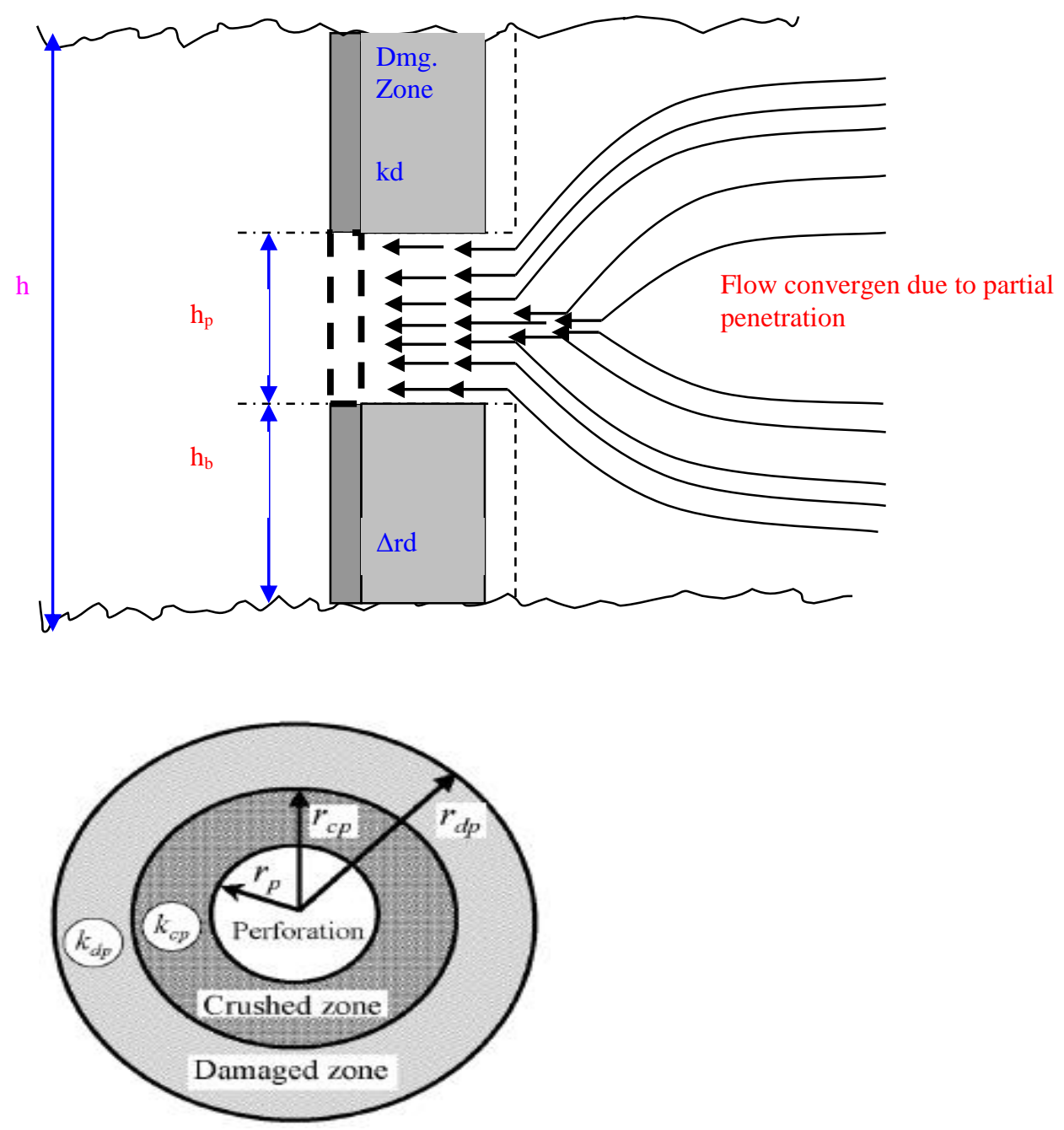

Gambar 2. Penampang Damage Zone

\section{Perhitungan Produktivitas Indeks}

$$
\mathrm{PI}=\frac{\mathrm{q}}{\mathrm{Ps}-\mathrm{Pwf}} ; \mathrm{bbl} / \mathrm{d} / \mathrm{psi}
$$


PI juga dapat ditentukan dari persamaan yang lain yaitu:

$$
\mathrm{PI}=\frac{7.08 \times 10^{-3} \mathrm{k} \cdot \mathrm{h}}{\mu_{\mathrm{o}} \mathrm{B}_{o}(\ln \mathrm{re} / \mathrm{rw}-0.75+\mathrm{S})}
$$

\section{PERHITUNGAN KERUSAKAN FORMASI AKIBAT PEKERJAAN PERFORASI PADA SUMUR FR 168, FR 154 DAN FR 148.}

Untuk mengaplikasi teori dari Yeldiz, diambil data lapangan pada sumur kajian

Data lapangan yang digunakan untuk perhitungan

Tabel 3 : Data aktual sumur kajian

\begin{tabular}{|c|c|c|c|c|c|c|c|c|c|c|c|c|c|}
\hline \multirow{2}{*}{ No } & Type Gun & \multirow{2}{*}{ Well } & Sand & \multirow{2}{*}{ K (mD } & \multicolumn{2}{|c|}{ Perforasi (ft) } & Set Pompa (ft) & \multirow{2}{*}{ SFL } & WFL & $\begin{array}{c}\text { Q Aktual, } \\
\text { bfpd }\end{array}$ & $\begin{array}{c}\text { PI Aktual, } \\
\text { bpd/psi }\end{array}$ \\
\hline 1 & 34JL ULTRAJET & FR168 & B & 35 & 4936 & 4950 & 5128 & - & 95 & 4373 & 105.6 & 0.06 \\
\hline 2 & 34B HYPERJET II & FR154 & B & 245 & 4696 & 4733 & 4950 & 4928 & 215.7 & 1817 & 855.36 & 1.39 \\
\hline 3 & 34B HYPERJET II & FR148 & B & 204 & 4921 & 4927 & 5015 & 4946 & 563 & 4566 & 115.2 & 0.07 \\
\hline
\end{tabular}

\section{Perhitungan Skin Dengan menggunakan metoda Yildiz.}

Perhitungan dengan metoda Yildiz dapat dilihat pada lampiran dan hasil perhitungan dapat dilihat pada table dibawah ini :

Tabel 4.:Total skinP ada Segmen Perforasi

\begin{tabular}{|c|c|c|c|r|r|}
\hline \multirow{2}{*}{ No } & \multirow{2}{*}{ Well } & \multicolumn{2}{|c|}{ Perforasi (ft) } & \multirow{2}{*}{ Spp } & \multirow{2}{*}{ St } \\
\cline { 3 - 4 } & & Top & Bott & & \\
\hline 1 & FR 168 & 4936 & 4950 & 0,496 & 6,835 \\
\hline 2 & FR 154 & 4696 & 4733 & 0,241 & 6,784 \\
\hline 3 & FR 148 & 4921 & 4927 & 0,605 & 7,610 \\
\hline
\end{tabular}

\section{Perhitungan Produktivitas Indeks}

$$
\begin{aligned}
P I & =\frac{7.08 * 10^{-3} k_{o} \cdot h}{\mu_{o} B_{o}\left[\ln \left(\frac{r e}{r w}\right)-0.75+S t\right]} \\
P I & =\frac{7.08 * 10^{-3}(35)(4950-4936)}{(2.4) *(1.108)\left[\ln \left(\frac{500}{0.5}\right)-0.75+6.835\right]} \\
= & 0.10 \mathrm{bpd} / \mathrm{psi}
\end{aligned}
$$


Tabel 5 : Produktivitas Indeks Pada Satu Segmen Perforasi

\begin{tabular}{|c|c|c|c|c|r|r|r|}
\hline No & Well & ht,ft & hp,ft & hb,ft & St & $\begin{array}{r}\text { PIactual, } \\
\text { BPD/Psi }\end{array}$ & $\begin{array}{c}\text { PI,BPD/Psi } \\
\text { (Yildiz) }\end{array}$ \\
\hline 1 & FR 168 & 20 & 14 & 4 & 6,83 & 0,06 & 0,10 \\
\hline 2 & FR 154 & 46 & 37 & 7 & 6,78 & 1,39 & 1,86 \\
\hline 3 & FR 148 & 22 & 6 & 13 & 7,61 & 0,07 & 0,24 \\
\hline
\end{tabular}

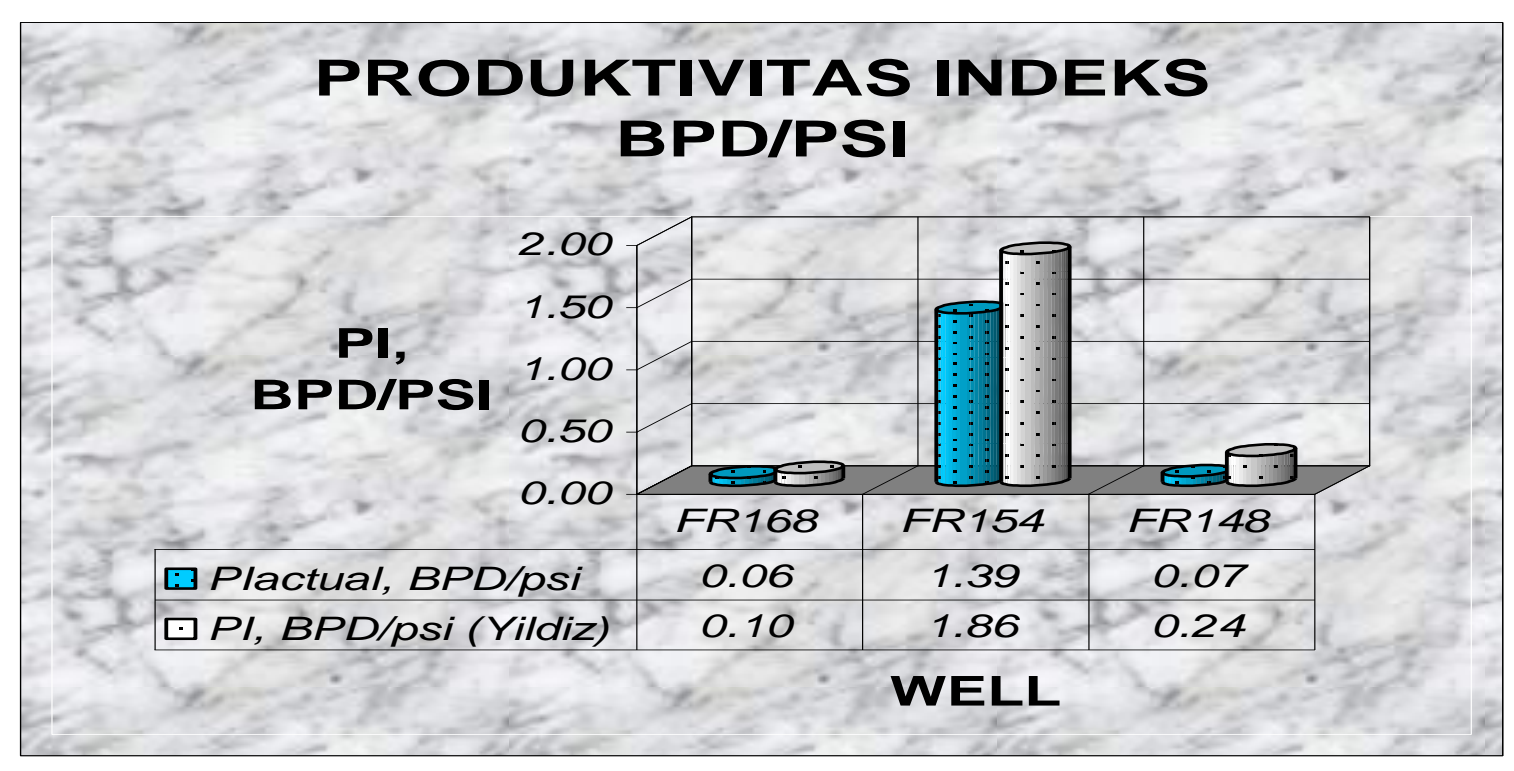

Gambar 3: Perbandingan produktivitas indeks aktual dengan produktivitas perhitungan pada segment perforasi

\section{Perhitungan Laju Alir Produksi}

Setelah produktivitas indeks di hitung, maka laju produksi dapat dihitung dengan persamaan berikut :

$$
\begin{aligned}
q & =P I(\operatorname{Pr}-P w f) \\
q & =0.08(1899.612-223.5) \\
& =168.297 b f p d
\end{aligned}
$$

Untuk lebih jelasnya perhitungan ini, lihat tabel 6 dibawah ini

Tabel 6 : Laju Produksi Dan Produktivitas Indeks Pada Pada Segmen Perforasi Setiap Masing-Masing Sumur kajian 


\begin{tabular}{|c|c|c|r|}
\hline No & Well & PI,BPD/psi (Yildiz) & $\begin{array}{c}\text { Q, } \\
\text { bfpd(Yildiz) }\end{array}$ \\
\hline 1 & FR 168 & 0.10 & 168.297 \\
\hline 2 & FR 154 & 1.86 & 1151.533 \\
\hline 3 & FR 148 & 0.24 & 371.271 \\
\hline
\end{tabular}

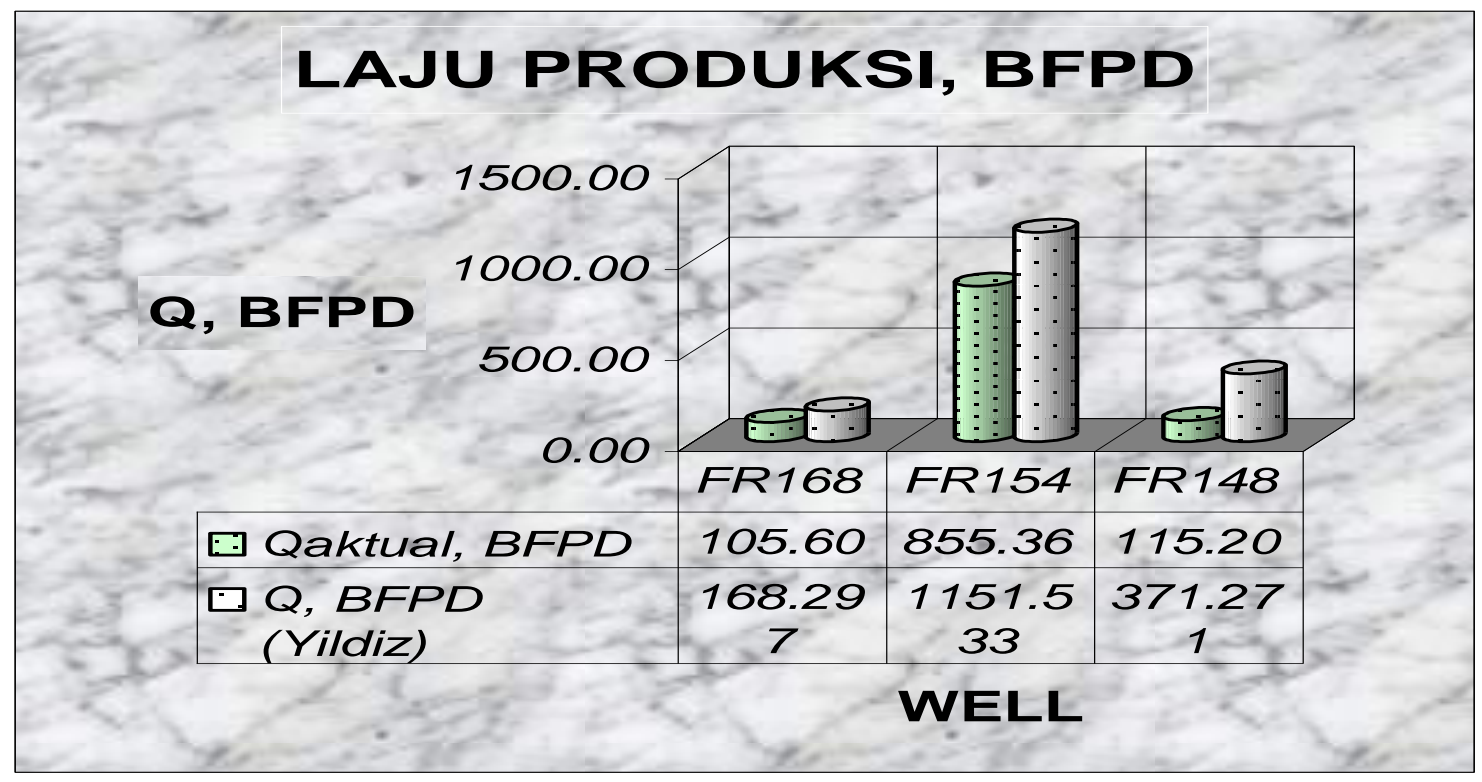

Gambar 4. Perbandingan laju produksi aktual dengan laju produksi Yildiz pada segmen perforasi

\section{PEMBAHASAN}

Membahas skin yang diakibatkan oleh perforasi. Berdasarkan data-data sumur yang telah diseleksi sebelumnya. Besarnya zona yang rusak "Crushed Zone" yang dibentuk oleh Gun Perforasi yang mengakibatkan adanya hambatan aliran atau skin, sehingga dapat diketahui pengaruhnya terhadap laju produkstivitas fluida reservoir yang diterapkan dalam sumur kajian, dimana hasil dari perhitungan dengan menggunakan metoda Yildiz ini dapat digunakan sebagai bahan pertimbangan untuk membandingkan dengan kenyataan produksi di lapangan. Metoda Yildiz digunakan karena metoda ini memperhitungkan kerusakan formasi baik secara vertikal secara horizontal dan secara lateral dan lebih refresentative dibandingkan dengan metoda lain atau dengan Program SPAN. Dari hasil perhitungan pada satu segmen perforasi diperoleh skin totalnya bernilai positif seperti terlihat pada table dibawah ini. 
Tabel 7 : Skin total pada satu segmen perforasi setiap sumur-sumur kajian

\begin{tabular}{|c|l|c|r|r|r|}
\hline \multirow{2}{*}{ No } & \multirow{2}{*}{ Well } & \multicolumn{2}{|c|}{ Perforasi (ft) } & \multirow{2}{*}{ Spp } & \multirow{2}{*}{ St } \\
\cline { 3 - 4 } & & Top & Bott & & \\
\hline 1 & FR168 & 4936 & 4950 & 0.496 & 6.835 \\
\hline 2 & FR154 & 4696 & 4733 & 0.807 & 6.784 \\
\hline 3 & FR148 & 4921 & 4927 & 0.605 & 7.610 \\
\hline
\end{tabular}

Dari nilai skin tersebut, dilakukan perhitungan terhadap produktivitas indeknya, dari hasil perhitungan tersebut pada sumur FR168 dengan nilai skin 6,835 produktivitasnya 0,10 bpd/psi, sumur FR154 skinnya 6,784 produktivitasnya 1,86 bpd/psi, dan pada sumur FR148 produktivitasnya $0.24 \mathrm{bpd} / \mathrm{psi}$. Dari hasil produktivitas indeks dapat dipersentase errrornya terhadap data aktual lapangan, yang mana pada sumur FR168 persentase errornya sebesar $0.67 \%$, sumur FR154 sebesar $0.34 \%$, dan sumur 148 sebesar $2.38 \%$.

Setelah produktivitas indek dihitung kemudian dilakukan perhitungan terhadap laju produksinya. Dari hasil perhitungan laju produksi dapat dipersentase errornya terhadap data aktual lapangan, yang mana pada sumur FR168 persentase errornya sebesar 0.59\%, sumur FR154 persentase errornya sebesar $0.34 \%$, dan pada sumur FR148 persentase errornya sebesar 2.22\%. Hasil perhitungan PI dan laju alir lebih besar dari aktual, hal ini disebabkan kurang teliti dalam pengambilan data, mengingat data yang dibutuhkan sangat bervariasi dan tingkat kesulitannya sangat tinggi.

\section{KESIMPULAN}

1. Dari hasil perhitungan pada segmen perforasi, menunjukkan nilai skin yang positif, yang berarti pada ketiga sumur kajian tersebut mengalami kerusakan akibat pekerjaan perforasi.

2. Harga skin total (St) akibat adanya pekerjaan perforasi berturut turut adalah 6,835 , 6,784 dan 7,610, untuk sumur FR168,154 dan 148, sedangkan harga PI berturut-turut adalah 0,10 bpd/psi, 1,86 bpd/psi dan 0.24 bpd/psi. untuk sumur FR168,154 dan 148

3. Laju aliran dari hasil perhitungan dan PI metoda Yildiz ini lebih besar atau tidak terlalu mendekati terhadap Q aktualnya, Hal ini disebabkan karena kurangnya ketelitian dan tingkat kesulitannya sangat tinggi dalam pengambilan data.

\section{DAFTAR PUSTAKA}

1. Brown, Kermit E., “The Artificial Lift Method Volume 4", Penn Well Publishing Company Tulsa, Oklahoma. 
2. Guerra. E, SPE, and Yildiz. T, SPE, “A Simple Approximate Method To Predict Inflow Performance Of Selectively Perforated Vertical Well" Colorado School Of Mines,

3. Karakas, Metin and Tarig. S.M, "Semi analytical Produktivity Models for Perforated Completions". SPE, Schlumberger Well Service (SPE 18247)..

4. Yildiz,Turhan, "Assessment Of Total Skin Faktor in Perforated Well", Colorado School of Mines, (SPE 82249)

5. Yildiz,Turhan, "Produvtivity Of Selectively Perforated Vertical Well", U. Of Tulsa, (SPE 82358)

\section{DAFTAR SIMBOL}

Hd : Jarak vertikal antara dua perforasi, ft. $\quad$ Lp $\quad$ : Kedalaman penetrasi, $\mathrm{ft}$

$\mathrm{k}_{\mathrm{H}} \quad$ : Permeabilitas horizontal, md.

$\mathrm{k}_{\mathrm{v}} \quad$ : Permea vertikal, md

h : Jarak vertikal perforasi, ft.

Lp : Kedalaman penetrasi, $\mathrm{ft}$

$\mathrm{k} \quad$ : Permeabilitas formasi, md.

$\mathrm{r}_{\mathrm{c}} \quad$ : Jari-jari terkompaksi, $\mathrm{ft}$

$\mathrm{k}_{\mathrm{c}} \quad$ : Permeabilitas zona terkompaksi, md.

$\mathrm{r}_{\mathrm{p}} \quad$ : Radius perforasi, $\mathrm{ft}$

$\mathrm{k}_{\mathrm{d}} \quad$ : Permeabilitas damage, md.

$\mathrm{r}_{\mathrm{d}} \quad$ : jari-jari damage, $\mathrm{ft}$

$\mathrm{r}_{\mathrm{w}} \quad$ : Jari-jari sumur, ft.

Sp : Skin partial komplesi

kv : Permebilitas vertikal, $\mathrm{mD}$.

Kh $\quad$ : Permea horizontal, $\mathrm{mD}$

$\mathrm{H} \quad$ : Ketebalan zona produktif, $\mathrm{ft}$.

ks : permea formasi, md

$\mathrm{q}_{\mathrm{p}} \quad$ : Laju alir fluida menuju lubang sumur pada sumur diperforasi, bpd

Sp : Faktor skin akibat perforasi $\quad$ Lp $\quad$ Panjang perforasi, $\mathrm{ft}$

kf : Permeabilitas zona skin.md. $\quad h_{p} \quad:$ ketebalan perforasi,ft

$h_{b} \quad$ : Jarak antara bottom perforasi dengan dan bottom zona yang produktif (reservoir), $\mathrm{ft} \quad \mathrm{n}_{\mathrm{spf}} \quad$ : jmlh shot per foot.

$\mathrm{k}_{\mathrm{cz}} \quad$ : Permeabilitas pada crushed zone, $\mathrm{mD}$

$\mathrm{r}_{\mathrm{cz}} \quad$ : Radius crushed zone disekitar perforasi. Ft

$\mathrm{S}_{\mathrm{cz}} \quad$ : Skin pada batuan yang terkompaksi disekitar perforasi

Dalam formasi damage Sd : Skin formasi damage.

Spd : Skin total gabungan aliran konvergen kearah perforasi Dan formasi damage

\section{LAMPIRAN}


1. $h_{p D}=\frac{h_{p}}{h}=\frac{14}{20}=0.7 f t$

2. $h_{b D}=\frac{h_{b}}{h}=\frac{4}{20}=0.2 f t$

3. $D=\left|\frac{\left(1-h_{p D}\right)}{2-h_{b D}}\right|=\left|\frac{(1-0.7)}{2-0.2}\right|=0.167 f t$

4. $r_{w D}=r_{w} \sqrt{\frac{\left(\frac{k_{z}}{k_{r}}\right)}{h}}=0.5 \sqrt{\frac{1}{20}}=0.112 \mathrm{ft}$

5. $z_{1}=1-2 D=1-(2 * 0.167)=0.667 f t$

6. $z_{2}=1-2 D+h_{p D}=1-(2 * 0.167)+0.7$

7. $z_{3}=1-2 D-h_{p D}$

$$
=1-(2 * 0.167)-0.7
$$$$
=-0.033 \mathrm{ft}
$$

8. $g(y)=r_{w D} * \frac{\ln \left[\sin ^{2}\left(\frac{\pi * y}{2}\right)+0.1053 * r_{w D}^{2}\right]}{\pi}$

$$
\begin{aligned}
g\left(h_{p D}\right) & =r_{w D} * \frac{\ln \left[\sin ^{2}\left(\frac{\pi * h_{p D}}{2}\right)+0.1053 * r_{w D}^{2}\right]}{\pi} \\
& =0.112 * \frac{\ln \left[\sin ^{2}\left(\frac{3.14 * 0.7}{2}\right)+0.1053 * 0.112^{2}\right]}{3.14} \\
& =-0.008 \mathrm{ft}
\end{aligned}
$$

9. $f(y)=y * \ln y+(2-y) * \ln (2-y)+g(y)$

$$
\begin{aligned}
f\left(h_{p D}\right) & =h_{p D} * \ln h_{p D}+\left(2-h_{p D}\right) * \ln \left(2-h_{p D}\right)+g\left(h_{p D}\right) \\
& =0.7 * \ln 0.7+(2-0.7) * \ln (2-0.7)+g(-0.008) \\
& =0.083 \mathrm{ft}
\end{aligned}
$$

10. $F=f(0)-f\left(h_{p D}\right)+f\left(z_{1}\right)-0.5\left[f\left(z_{2}\right)+f\left(z_{3}\right)\right]$

$$
\begin{aligned}
& =1.150-0.083+0.103-0.5[0.125+1.247] \\
& =-0.484 f t
\end{aligned}
$$


11. $S_{p p}=\left(\frac{1}{h_{p D}}-1\right) *\left(1.2704-\ln r_{w D}\right)-\frac{F}{h_{p D}^{2}}$

$=\left(\frac{1}{0.7}-1\right) *(1.2704-\ln (0.112))-\frac{-0.484}{0.7^{2}}=0.496 f t$

$$
\begin{aligned}
& k_{d}=\left(\frac{1}{8}\right) * k=\left(\frac{1}{8}\right) * 245, \quad S_{d}=\left(\frac{k}{k_{d}}-1\right) * \ln \left(\frac{r_{d}}{r_{w}}\right) \\
&= 30.625 \\
&=\left(\frac{245}{30.625}-1\right) * \ln \left(\frac{(0.5+1)}{0.5}\right) \\
& \quad=7.6903 f t \\
& S_{p}=S_{H}+S_{V}+S_{w b} \\
&=(-1.3869)+0.2341+0.0058=-1.3513
\end{aligned}
$$

12. $S t=S_{d}+S_{p p}+S_{p}$

$$
\begin{aligned}
& =7.6903+0.496+(-1.3513) \\
& =6.835
\end{aligned}
$$

